\title{
Determination of the Oxygen and Nitrogen Interstitial Diffusion Coeficient in Niobium by Mechanical Spectroscopy
}

\author{
Odila Florêncio a*, Paulo Sergio da Silva Jr., Thais França Stefaninia, Carlos Roberto Grandini ${ }^{\mathrm{b}}$ \\ ${ }^{a}$ Laboratório de Metalurgia Física, Departamento de Física, \\ Centro de Ciências Exatas e de Tecnologia, Universidade Federal de São Carlos, \\ Rodovia Washington Luiz, Km 235, 13565905 São Carlos - SP, Brazil \\ ${ }^{\mathrm{b}}$ UNESP, Faculdade de Ciências, C. P. 473, 17033-360 Bauru - SP, Brazil
}

Received: August 11, 2006; Revised: November 11, 2006

\begin{abstract}
Mechanical spectroscopy measurements have been extensively used in the last decades to obtain information about many aspects of the behavior of solutes in metallic materials. Metals of body-centered cubic lattice that contain heavy interstitial elements (oxygen, nitrogen and carbon) in solid solution, present anelastic relaxation peaks when submitted to cyclic tensions, due to process know stress-induced ordering. Internal friction and frequency as a function of temperature were performed between $300 \mathrm{~K}$ and $650 \mathrm{~K}$ in a polycrystalline sample of $\mathrm{Nb}$, for three distinct conditions, using a torsion pendulum inverted Kê-type operating in a frequency oscillation between $1 \mathrm{~Hz}$ and $10 \mathrm{~Hz}$ range, with a heating rate of $1 \mathrm{~K} / \mathrm{min}$ and pressure lower than $2 \times 10^{-5} \mathrm{mbar}$. The experimental spectra obtained for each condition of the sample, were decomposed by the successive subtraction method in elementary Debye peaks. The following metal-interstitial interactions were identified: $\mathrm{Nb}-\mathrm{O}$ and $\mathrm{Nb}-\mathrm{N}$ for all conditions of the sample. From the anelastic relaxation parameters obtained (relaxation strength, peak temperature, activation energy and relaxation time) and lattice parameter (obtained from x ray diffraction), the determination of the oxygen and nitrogen interstitial diffusion coefficient in $\mathrm{Nb}$ was possible, for each condition of the sample.
\end{abstract}

Keywords: interstitial diffusion, niobium, internal friction, oxygen, nitrogen

\section{Introduction}

When a tension wave is applied in a crystalline material, occur the interaction this tension wave with the defects present in solid, causing the energy loss. The energy loss is due to local motion of some micro-structural unit, such interstitials and substitutional atoms, vacancies and dislocations.

Materials containing solute atoms dissolved interstitially often show anelastic behavior due to a process know as stress-induced ordering. Point defects in solids can give rise to anelastic relaxation provided that the defects behave as elastic dipoles. Elastic dipoles represent atomic defects the produce an anisotropic local distortion of the crystal lattice. Heavy interstitial atoms, such as $\mathrm{O}, \mathrm{N}$, or $\mathrm{C}$, in body centered-cubic (BCC) metals induce elastic dipoles with tetragonal symmetry. The stress-induced ordering of the dipoles is the elementary step of interstitial diffusion. One manifestation this anelastic behavior is the internal friction, which was originally described by Snoek $^{1}$ in iron $(\mathrm{Fe})$ containing carbon and nitrogen as interstitial solutes.

Mechanical relaxation measurements have been used to obtain information about many aspects of behavior of solutes in metals, for example, matrix-solute interactions ${ }^{1}$, interstitial-interstitial and substitutional-interstitial interactions ${ }^{2-4}$, interstitial diffusion ${ }^{5,6}$, etc.

For materials of the BCC lattice, when solute species only jumps between octahedral sites occur, the interstitial diffusion coefficient (D) is described ${ }^{5-6}$ :

$$
D=\frac{a^{2}}{36 \tau}
$$

where $a$ correspond the lattice parameter of material and $\tau$ is the relaxation time.

Several techniques can be used to internal friction measurements $^{7-9}$, of these the torsion pendulum has been frequently used to study of the heavy interstitial solute interactions such as carbon, oxygen and nitrogen.

In the present work, internal friction and frequency were measured as a function of temperature in an $\mathrm{Nb}$ sample containing oxygen and nitrogen in solid solution, for three different conditions: (A) as received sample, (B) annealed and (C) annealed followed by a treatment in a oxygen atmosphere during three hours.

\section{Materials and Experimental Procedure}

The polycrystalline sample of $\mathrm{Nb}$ was obtained by electron-beam zone melting and was supplied in the form of swaged rod of $3 \mathrm{~mm}$ in diameter, by FAENQUIL/Lorena. Samples $50 \mathrm{~mm}$ long which had been chemically polished to $1 \mathrm{~mm}$ diameter in a mixture of nitric and fluoric acids, were used for the internal friction and $\mathrm{x}$ ray diffraction (XRD) measurements.

The values of internal friction and frequency were obtained with a torsion pendulum of the inverted Kê-type ${ }^{10}$ which was set to give rise an oscillation frequency between $1 \mathrm{~Hz}$ and $10 \mathrm{~Hz}$, with a heating rate of $1 \mathrm{~K} / \mathrm{min}$ and pressure lower than $2 \times 10^{-5} \mathrm{mbar}$. The data of oscillation decay were collected automatically by two photodiodes connected to a computer. The internal friction was determined from the amplitude decay, which was determined by ratio of the two measured transit times, the frequency was determined from period of oscillation.

Experimental spectra of anelastic relaxation were obtained for three conditions of the sample: (A) as received sample; (B) annealed sample, during two hours, in a temperature of $1170 \mathrm{~K}$ and pressure of $2.5 \times 10^{-8}$ mbar and (C) annealed followed by a treatment in a oxygen atmosphere during three hours, in a temperature of $1170 \mathrm{~K}$ at oxygen partial pressure of $5 \times 10^{-5} \mathrm{mbar}$. The lattice parameter of 
the $\mathrm{Nb}$ sample was determined by XRD (powder method) for each sample condition.

The internal friction curves as a function of temperature were resolved into elemental Debye peaks ${ }^{11}$ using the method of successive subtraction (in the present work, Peak Fitting Module of Origin was used). The anelastic processes were identified, and the relevant parameters (activation energy, relaxation strength, peak temperature, relaxation time) of each of the process were obtained.

With the anelastic relaxation parameters obtained and lattice parameter, the determination of the oxygen and nitrogen interstitial diffusion coefficient in $\mathrm{Nb}$ was possible, for each condition of the sample.

\section{Results and Discussion}

Experimental spectra of anelastic relaxation as a function of temperature have been obtained for the $\mathrm{Nb}$, for three distinct conditions of sample as described above. The chemical analysis of the interstitial impurities in the metals as-received condition was 0.016 at- $\%$ of the oxygen and 0.015 at- $\%$ of the nitrogen.

XRD spectra revealed only peaks related to the cubic structure for all conditions for the $\mathrm{Nb}$ sample. The results obtained from XRD for lattice parameter for each condition of sample were following: (A) $\mathrm{a}=(3.295 \pm 0.001) \AA$, (B) $\mathrm{a}=(3.301 \pm 0.002) \AA$ and (C) $(3.297 \pm 0.001) \AA$.

Figure 1 shows experimental spectrum of anelastic relaxation of $\mathrm{Nb}$ sample, as received (A), that were resolved into two constituent peaks of Debye corresponding to the interactions $\mathrm{Nb}-\mathrm{O}$, and $\mathrm{Nb}-\mathrm{N}$. These data were obtained oscillation frequency of $4.0 \mathrm{~Hz}$ (at room temperature). Other measurements were carried out at this sample using oscillations frequency about $1.4 \mathrm{~Hz}, 2.8 \mathrm{~Hz}, 2.9 \mathrm{~Hz}$ and $4.1 \mathrm{~Hz}$ (at room temperature). The increase of internal friction spectrum background is associated of plastic deformation of the Nb sample.

Figure 2 shows the internal friction and oscillation frequency as a function of temperature for the $\mathrm{Nb}$ sample, after annealing during two hours at $1170 \mathrm{~K}$ and pressure of $2.5 \times 10^{-8} \mathrm{mbar}(\mathrm{B})$. This experimental spectrum of anelastic relaxation was resolved into two elemental Debye peak, associates the matrix-interstitial interactions Nb-O and $\mathrm{Nb}-\mathrm{N}$. These data were obtained with an oscillation frequency about $4.1 \mathrm{~Hz}$ (at room temperature). Others data were obtained for this condition of the sample using oscillations frequency about $1.4 \mathrm{~Hz}, 2.4 \mathrm{~Hz}$, $2.9 \mathrm{~Hz}$ and $8.2 \mathrm{~Hz}$ (at room temperature). After sample annealing, the grown of the internal friction background was attenuated.

Figure 3 shows anelastic spectrum of $\mathrm{Nb}$ sample, after annealed followed by a treatment in an oxygen atmosphere during three

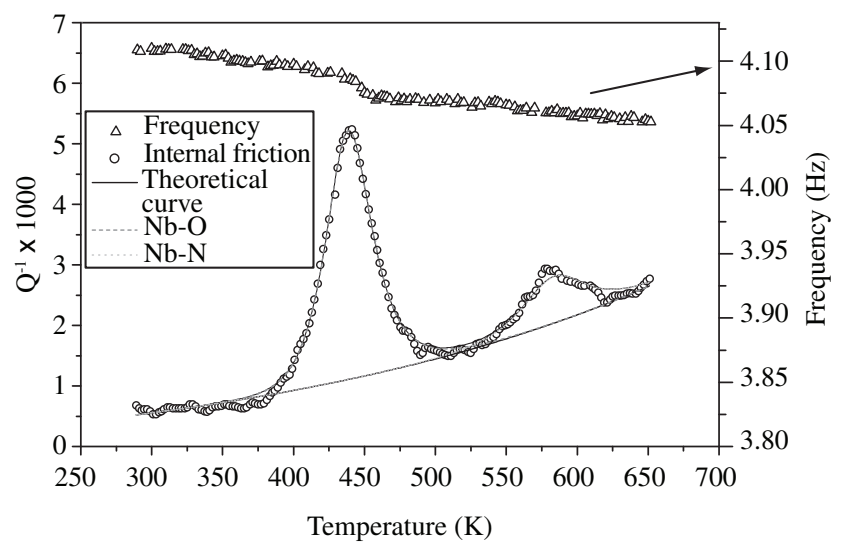

Figure 1. Internal friction and oscillation frequency as a function of temperature for $\mathrm{Nb}$ sample, as received, resolved into constituent peaks corresponding to the interactions: $\mathrm{Nb}-\mathrm{O}$ and $\mathrm{Nb}-\mathrm{N}$. hours, in a temperature of $1170 \mathrm{~K}$ in oxygen at a partial pressure of $5 \times 10^{-5} \mathrm{mbar}(\mathrm{C})$. These experimental spectrums were decomposed into two relaxation processes, associates the matrix-interstitial interactions: $\mathrm{Nb}-\mathrm{O}$ and $\mathrm{Nb}-\mathrm{N}$, however with the highest relaxation strength which is attributed to the greater amount of interstitial oxygen in solid solution. This data were obtained with an oscillation frequency about $2.9 \mathrm{~Hz}$, and others measurements were carried out using oscillation frequency about $1.4 \mathrm{~Hz}, 2.4 \mathrm{~Hz}$ and $4.1 \mathrm{~Hz}$, these values at room temperature.

Assuming that the peaks are true Debye peaks, one can compute the activation energies (E) for the processes, measuring the width at half of the peak height. Using the condition of Debye peak $(\omega \tau=1)$, have been determined the relaxation time $(\tau)$, for each one of relaxation processes. Table 1 shows the parameters of anelastic relaxation for each kind of interaction and all conditions of $\mathrm{Nb}$ sample, for oscillation frequency about $4.1 \mathrm{~Hz}$.

The contamination of the $\mathrm{Nb}$ sample during annealing is evident, being observed the increase of the intensity of the peaks from Figure 2 and Table 1.

The broadening of oxygen Snoek peak and shift of peak temperature from Figure 3 is associated the increase of interstitial concentration of oxygen due to treatment in an oxygen atmosphere. This indicate the presence of more that one relaxation process, but, according to Povolo and Lambri ${ }^{12}$ don't exist one physical model that

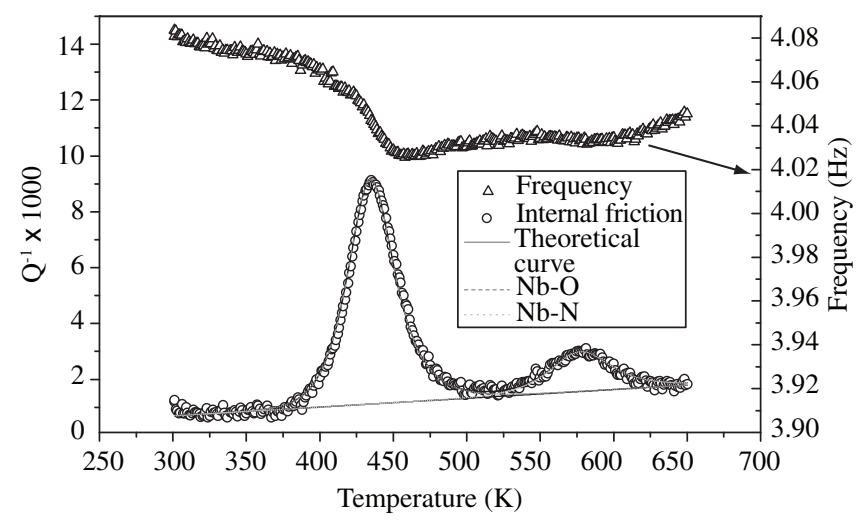

Figure 2. Internal friction and oscillation frequency as a function of temperature for $\mathrm{Nb}$ sample, for (B) condition, resolved into constituent peaks corresponding to the interactions: $\mathrm{Nb}-\mathrm{O}$ and $\mathrm{Nb}-\mathrm{N}$.

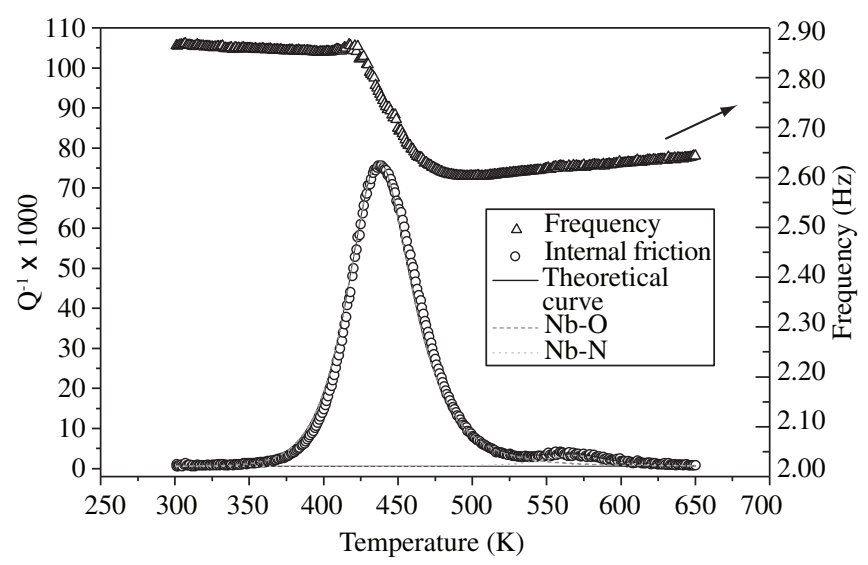

Figure 3. Internal friction and oscillation frequency as a function of temperature for $\mathrm{Nb}$ sample, for $(\mathrm{C})$ condition, resolved into constituent peaks corresponding to the interactions: $\mathrm{Nb}-\mathrm{O}$ and $\mathrm{Nb}-\mathrm{N}$. 


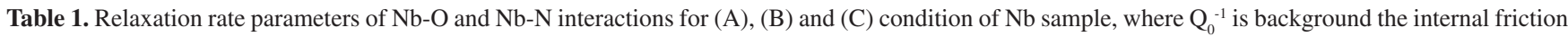
spectrum.

\begin{tabular}{|c|c|c|c|c|c|}
\hline Condition & $\mathrm{Q}^{-1} \max -\mathrm{Q}_{0}^{-1} \times 10^{3}$ & Interaction & $\mathrm{T}_{\text {peak }}(\mathrm{K})$ & $\mathrm{E}(\mathrm{eV})$ & $\tau(\mathrm{s})$ \\
\hline \multirow[t]{2}{*}{ (A) } & 4.11 & $\mathrm{Nb}-\mathrm{O}$ & 438 & 1.15 & $3.895 \times 10^{-2}$ \\
\hline & 0.78 & $\mathrm{Nb}-\mathrm{N}$ & 584 & 1.52 & $3.920 \times 10^{-2}$ \\
\hline \multirow[t]{2}{*}{ (B) } & 8.03 & $\mathrm{Nb}-\mathrm{O}$ & 435 & 1.15 & $3.935 \times 10^{-2}$ \\
\hline & 1.43 & $\mathrm{Nb}-\mathrm{N}$ & 577 & 1.52 & $3.946 \times 10^{-2}$ \\
\hline \multirow[t]{2}{*}{ (C) } & 76.42 & $\mathrm{Nb}-\mathrm{O}$ & 442 & 0.90 & $4.065 \times 10^{-2}$ \\
\hline & 1.20 & $\mathrm{Nb}-\mathrm{N}$ & 570 & 1.52 & $4.274 \times 10^{-2}$ \\
\hline
\end{tabular}

Table 2. Interstitials diffusion coefficient (D) of oxygen and nitrogen in $\mathrm{Nb}$, for all conditions of the $\mathrm{Nb}$ sample.

\begin{tabular}{|c|c|c|c|c|}
\hline Condition & $\mathrm{T}_{\text {peak }}(\mathrm{K})$ & Interaction & $\mathrm{D} \times 10^{16}\left(\mathrm{~cm}^{2} / \mathrm{s}\right)$ & $\mathrm{D} \times 10^{16 *}\left(\mathrm{~cm}^{2} / \mathrm{s}\right)$ \\
\hline \multirow[t]{4}{*}{ (A) } & 428 & $\mathrm{Nb}-\mathrm{O}$ & 5.332 & 3.372 \\
\hline & 579 & $\mathrm{Nb}-\mathrm{N}$ & 5.305 & 3.567 \\
\hline & 438 & $\mathrm{Nb}-\mathrm{O}$ & 7.743 & 6.897 \\
\hline & 584 & $\mathrm{Nb}-\mathrm{N}$ & 7.694 & 4.715 \\
\hline \multirow[t]{4}{*}{ (B) } & 429 & $\mathrm{Nb}-\mathrm{O}$ & 4.661 & 3.627 \\
\hline & 570 & $\mathrm{Nb}-\mathrm{N}$ & 4.647 & 2.098) \\
\hline & 434 & $\mathrm{Nb}-\mathrm{O}$ & 7.692 & 5.201 \\
\hline & 577 & $\mathrm{Nb}-\mathrm{N}$ & 7.670 & 3.186 \\
\hline \multirow[t]{4}{*}{ (C) } & 437 & $\mathrm{Nb}-\mathrm{O}$ & 5.261 & 6.430 \\
\hline & 567 & $\mathrm{Nb}-\mathrm{N}$ & 4.970 & 1.789 \\
\hline & 447 & $\mathrm{Nb}-\mathrm{O}$ & 9.176 & 12.777 \\
\hline & 575 & $\mathrm{Nb}-\mathrm{N}$ & 8.689 & 2.43 \\
\hline
\end{tabular}

*see G. Horz et al. ${ }^{13}$.

clearly explains feature of multiple peaks of mechanical relaxation in metals of BCC lattice, for high interstitial solute concentration.

Analyzing these results it is possible to estimate the amounts of interstitial elements in solid solution based in the paper of Ahmad and Szkopiak ${ }^{2}$. The estimated values are: 0.018 at- $\%$ of oxygen and 0.013 at- $\%$ of nitrogen for (A) condition of $\mathrm{Nb}$ sample, confirmed the analyses chemical nominal of $\mathrm{Nb}$ sample; 0.028 at- $\%$ of oxygen and 0.016 at- $\%$ of nitrogen for (B) condition of $\mathrm{Nb}$ sample and 0.350 at- $\%$ of oxygen and 0.015 at- $\%$ of nitrogen for $(\mathrm{C})$ condition. Oxygen was analyzed in a TC-436 DR equipment (Leco Co.) and result obtained was $(1.18 \pm 0.01)$ at $-\%$ of oxygen, this result is regarding total amount of oxygen in the $\mathrm{Nb}$ sample.

Interstitial elements in solid solution of metals with BCC lattice are responsible for the Snoek peaks in the relaxation spectrum of internal friction, due to the stress-induced ordering, i.e, diffusion process. Thus assuming that oxygen and nitrogen, for the concentrations present in the $\mathrm{Nb}$ sample, they have preferentially octahedral occupation in BCC lattice, can calculate of the interstitial diffusion coefficient of the oxygen and nitrogen in $\mathrm{Nb}$, using the Equation 1. Table 2 shows the interstitial diffusion coefficient of oxygen and nitrogen in $\mathrm{Nb}$, determined from mechanical spectroscopy.

Comparing of results obtained with literature data ${ }^{13}$, the coherence of the find values can be verified, confirmed the validity of technique for determination of interstitial diffusion coefficient, for the limit of solid solution diluted. In Table 2, a small deviation of interstitial diffusion coefficient values can be observed, compared with literature data, for $(\mathrm{C})$ condition of $\mathrm{Nb}$ sample. This difference can be explained by double occupation possibility (octahedral and tetrahedral), due to high concentration of interstitial impurities, reported by Boratto and Reed-Hill ${ }^{14}$. The region of validity of Equation 1 is the diluted solid solution, which as Ahmad and Szkopiak ${ }^{2}$ this concentration values could be lower at 0.035 at- $\%$ for oxygen and nitrogen in niobium.
Other factor that influences the results found is the difference between estimate concentrations in solid solution of oxygen (determined from mechanical spectroscopy) and determined by TC-436 DR equipment (which determine full concentration of impurities), which indicate the formation of precipitated.

\section{Conclusions}

1. The anelastic relaxation spectra for $\mathrm{Nb}$ samples containing different amounts of interstitial elements were obtained as a function of temperature with a torsion pendulum at oscillation frequency in the hertz bandwidth, for three conditions of $\mathrm{Nb}$ sample;

2. X ray diffraction revealed only peaks related to the cubic structure for all conditions for the $\mathrm{Nb}$ sample, and lattice parameter was determined;

3. The anelastic relaxation spectrum for $\mathrm{Nb}$ sample was resolved into two interactions processes: $\mathrm{Nb}-\mathrm{O}$ and $\mathrm{Nb}-\mathrm{N}$, for all conditions; and

4. From the parameters of anelastic relaxation for each kind of interaction (peak temperature, activation energy and relaxation time) and lattice parameter the determination of interstitial diffusion coefficient of oxygen and nitrogen in $\mathrm{Nb}$ was possible, for all condition of polycrystalline sample. Being results obtained coherent with literature data, confirmed the validity of technique for determination of interstitial diffusion coefficient, for the limit of solid solution diluted.

\section{Acknowledgments}

We would like to thank the following Brazilian agencies: FAPESP and $\mathrm{CNPq}$ for financial support. 


\section{References}

1. Snoek JL. Letter to editor. Physica. 1939; 6(1):591-591.

2. Ahmad MS, Szkopiak ZC. Snoek relaxation peaks in solid solutions of niobium Journal of Physics and Chemistry of Solids. 1970; 31(8):1799-1804.

3. Bunn PM, Cummings DG, Leavenworth Jr HW. Effect of zirconium on internal friction in columbium. Journal of Applied Physics. 1962; 33(10):3009-3013.

4. Szkopiak ZC, Smith JT. Internal-friction of Nb-1 at per cent substitutional alloys. Journal of Physics D. 1975; 8(11):1273-1284.

5. Powers RW, Doyle MV. Diffusion of interstitial solutes in the group-V transition metals. Journal of Applied Physics. 1959; 30(4):514-524.

6. Haneckzok G, Rasek J. Some applications of mechanical spectroscopy and magnetic relaxation techniques to the examination of diffusion processes in metals and alloys Defect and Diffusion Forum. 2001; 188(1):3-20.

7. Jordão JAR. Estudos de defeitos elásticos em sólidos: ultra-som e relaxação dielétrica, $\mathrm{PhD}$ thesis, Universidade de São Paulo, São Carlos, 1982.
8. Florêncio O, Pinatti DG, Roberts JM. The effect of static tensile bias stress upon the solubility limit of hydrogen in niobium crystals using the ultrasonic technique. Journal Physique. 1985; 46(C-10):115-118.

9. Botta FWJ, Florêncio O, Grandini CR, Tejima H, Jordão JAR. Mechanical multiple relaxation spectra in $\mathrm{Nb}-\mathrm{Zr}-\mathrm{O}$ alloys. Acta Metallurgica et Materialia. 1990; 38(3):391-396.

10. Kê TS. Experimental evidence of the viscous behavior of grain boundaries in metals. Physical Review. 1947; 71(8):533-546.

11. Nowick AS, Berry BS. Anelastic Relaxation in Crystalline Solids, First Edition, Academic Press, New York, US; 1972.

12. Povolo F, Lambri AO. Some considerations about the snoek relaxation in niobium-oxygen alloys. Materiais Transactions JIM. 1993; 34(1):33-36.

13. Jehn H, Speck H, Fromm E, Horz G. Physics Data: Gases and carbon in metals - Part. VIII: Nb, Fachinformationszentrum Energie-PhysikMathematik GmbH., Karlsruhe, DE; 1981.

14. Boratto FJM, Reed-Hill RE. Oxygen and nitrogen diffusion in tantalum. Scripta Metallurgica. 1978; 12(3):313-318. 